\title{
Sigmoid Volvulus in Late Pregnancy
}

\author{
$J$ P Keating \\ $\mathrm{MB}, \mathrm{BS}$ (Hons) \\ St Peter's Hospital, Chertsey \\ ${ }^{*}$ Major D S Jackson \\ $M B, C h B, F R C S(E d)$, RAMC
}

SUMMARY: Sigmoid volvulus in late pregnancy is an uncommon complication. We report a case of a 35 year old Caucasian?
woman who presented with symptoms and signs of intestinal obstruction when 34 weeks pregnant. Surgical management
of the case is described and the literature reviewed.

\section{Case Report}

Mrs E H, a 35 year old Caucasian, gravida 2, para 1, whose L M P was $3 / 7 / 83$, presented at mid-day on $25 / 2 / 84$ with colicky abdominal pain, distension, vomiting and constipation of 12 hours duration. She had noticed her own visible peristalsis and increased bowel sounds, coincidental with severe pains. During her previous pregnancy she had developed similar symptoms which were less severe and had subsided completely after parturition. There was nothing else of note in the past obstetric or medical history and apart from the uterus being displaced to the right side of the abdomen, no abnormalities or complications had been detected at routine antenatal surveillance.

On examination she was apyrexial, pulse $100 / \mathrm{min}$, BP $120 / 70$, tongue dry and she was not in pain. Her abdomen was very distended and an enlarged uterus, consistent with a 34 week gestation, was displaced to the right. Foetal heart sounds were normal and the presentation cephalic, the head not engaged. The whole of the left side of the abdomen was tender and tympanitic, with increased borborygmi. The rectum was empty.

Investigations were as follows: $\mathrm{Hb} 15.4 \mathrm{~g} / \mathrm{dl}$. W B C 10.6. Electrolytes, amylase and chest $\mathrm{x}$-ray normal.

Plain abdominal X-ray confirmed the clinical suspicion of a hugely distended loop of large bowel occupying the left side of the abdomen and displacing the uterus to the right (Fig 1, Fig 2.).

A diagnosis of volvulus of the sigmoid colon was made and initially she was managed conservatively as similar episodes in her previous pregnancy had settled spontaneously. Several further episodes of pain and vomiting on the night of admission led to attempted decompression of the large bowel with a soft rubber flatus tube passed via a sigmoidoscope. The gravid uterus made it impossible for the instrument to be passed sufficiently to visualise the lumen of the bowel at the site of torsion, and immediate laparotomy was undertaken.

A long massively dilated redundant loop of sigmoid

* Military Wing, Musgrave Park Hospital, BFPO 801.

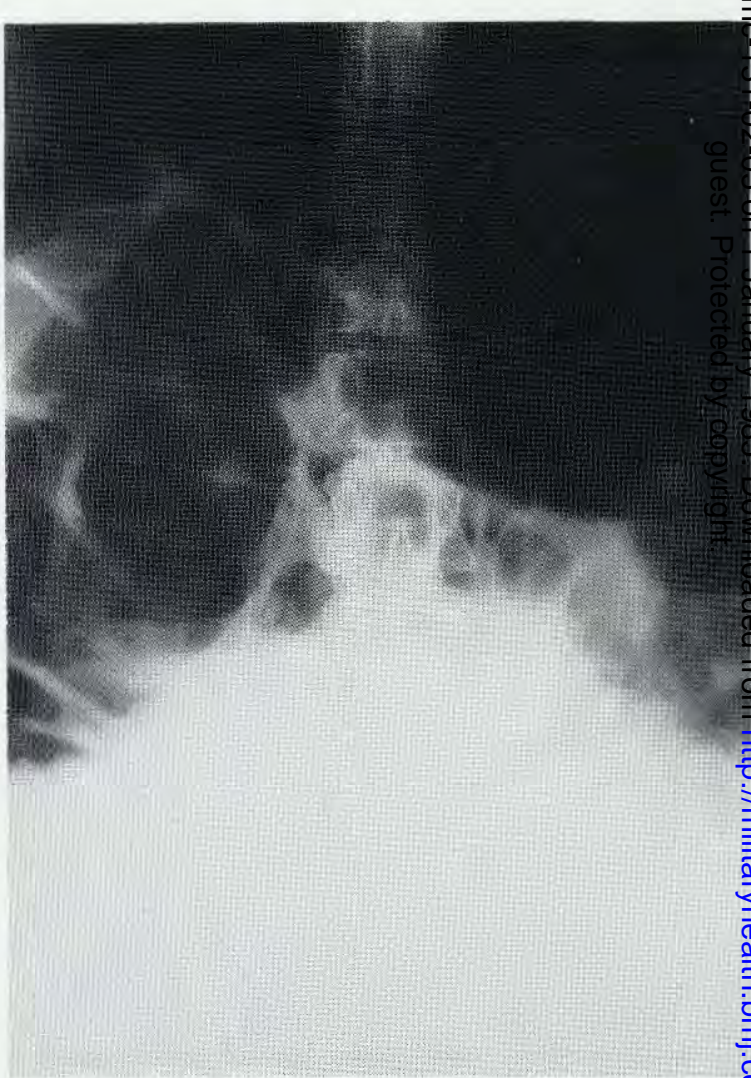

Fig 1 Top half of Plain Abdominal X-Ray.

colon was found twisted $120^{\circ}$ anti-clockwise on a long narrow mesocolon. Sigmoid colectomy was carried ouro and a double-barrelled sigmoid colostomy was establishec in the left iliac fossa with intervening skin bridge as faro as possible from the lower abdominal midline and suprapubic areas. The stomata were sutured by mucoN cutaneous suture. 


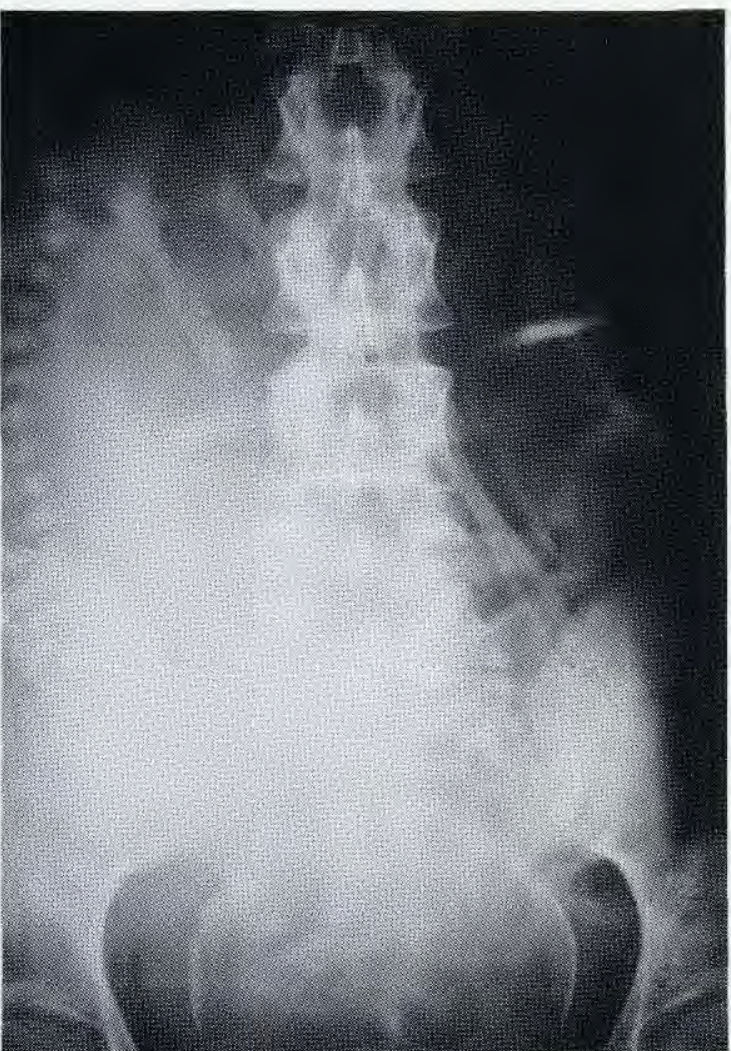

Fig 2 Bottom half of Plain Abdominal X-Ray.

The patient made an uneventful recovery and on 20 April, ten days after term, had a normal vaginal delivery of a healthy male infant, birth weight $3.5 \mathrm{~kg}$, afer induction by prostaglandin pessary. On 5 June 1984 continuity of the bowel was re-established by intraperitoneal anastomosis.

\section{Discussion}

Volvulus complicating pregnancy was first reported in 1885 by Braun following the death of his patient; the diagnosis was made at autopsy and involved the sigmoid colon. In 1958 Harer and Harer $^{1}$ reviewed the literature and accumulated a total of 112 cases of intestinal volvulus of pregnancy, with the sigmoid colon being most commonly involved $(52$ cases $-46 \%$ ) followed by the small bowel (31 cases-28\%), and elsewhere in the large bowel, primarily involving the caecum ( 28 cases $-25 \%$ ).

Rare as the condition is, they point out that volvulus is the commonest cause of intestinal obstruction in pregnancy, and a high index of clinical suspicion needs to be maintained.

The patient here described showed none of the features thought to predispose to sigmoid volvulus ${ }^{2}$, and at laparotomy no abnormality other than the redundant sigmoid loop and the narrow mesocolon was found. Several previously described cases of volvulus in pregnancy were found at laparotomy to have had predisposing causes, eg adhesions, previous salpingitis, and abnormalities of gastrointestinal development ${ }^{3}$.

Our patient's clinical history suggested a previous episode of volvulus when pregnant with her first child, but she had been asymptomatic at other times. This leads to the conclusion that pregnancy may predispose to volvulus. Kohn et al in 1944 reported recurrent volvulus of the sigmoid colon in a young woman who had four laparotomies, three for simple reduction of sigmoid volvulus and finally colectomy, during the course of two pregnancies. In their review they conclude that the only constant pathological finding in those cases of volvulus of the sigmoid colon was an elongated mesocolon.

Harer and Harer suggest that the mechanism of sigmoid volvulus in pregnancy is displacement, compression, and partial obstruction of an abnormally mobile sigmoid colon by the enlarging uterus. This would explain the increased incidence of volvulus in the third trimester, in accord with the conclusions of Kohn et al.

Volvulus in non-gravid women of childbearing years is very rare, and though it is probable that it occurs more frequently during pregnancy, there are no figures to $\mathbb{D}$ substantiate this.

Diagnostic difficulties may occur because symptoms can be identical to those of the onset of labour, and this was pointed out by James in his report in $1950^{4}$. His patient was primagravida, whereas our patient wase multiparous, and in the history volunteered that her symp-? toms were similar to but definitely not labour pains.

The management of volvulus of the sigmoid colon in pregnancy is surgical. Operation should be carried out as soon as possible as the mortality rate for both mother and child rises substantially with delay, more especially if non-viable bowel has to be resected ${ }^{3}$. Failure of intubation is an indication for laparotomy? $y^{7}$. We can find only two case reports, both published over 30 years ago, of early surgical intervention for sigmoid volvulus in late pregnancy. James ${ }^{4}$ managed his case by operative reduction and a flatus tube passed per anum to maintain decompression. Following delivery three weeks later, his patient was referred for surgical treatment of the redundant sigmoid colon.

O'Malley in his report of $1952^{5}$ decompressed the volvulus by colotomy, followed by reduction and construction of a vent colostomy to maintain decompression and prevent recurrence.

Our patient was treated by sigmoid colectomy with fashioning of a double-barrelled sigmoid colostomy. To the best of our knowledge this method of treatment has not been described previously. Simple reduction of the volvulus and decompression with a colonic tube passed per anum would have been inappropriate 6 weeks before term, with the likelihood of recurrence of the volvulus $(33-60 \%)^{6}$, on removal of the tube, even if operative fix- 
ation has been undertaken ${ }^{7}$. Primary anastomosis of an unprepared, distended, paretic and oedematous large bowel would have been hazardous to mother and foetus.

The stomata were deliberately sited well away from the elective areas of surgical incision for Caesarian section.

No medication was administered prophylactically to prevent the onset of premature labour, and in the event a normal vaginal delivery took place at term +10 days.

Large bowel continuity was re-established as a planned procedure six weeks later. There were no complications.

\section{ACKNOWLEDGEMENTS}

We would like to thank $\mathrm{Mr} \mathrm{A}$ Eley and $\mathrm{Mr} \mathrm{T}$ Spencer for permission to report this case, and also Mrs E J Mott for the preparation of the manuscript.

\section{REFERENCES}

I Harer W B JnR and Harer W B Snr. Volvulus Complicating Pregnancy and Puerperium. Obstet Gynecol 1958; $12: 4 ; 399-406$.

2 SHARPTON B and CHEEK R C. Volvulus of the sigmoid col on. The American Surgeon June 1976; 436-440.

3 KOHNS G, HENRY A B, DOUGi AsS L H. Volvulus complicating pregnancy. Am J Obstet Gynecol 1944; 48: 398-404. O

4 JAMES D W. Intestinal obstruction during late pregnancy $\overline{\bar{\omega}}$. caused by volvulus of sigmoid colon. Br Med $J 1950 ; 2 ; 24$. $\vec{\nabla}$

5 O'MALLEY R D. Volvulus and pregnancy. A case report with $\varrho$ recommendations for surgical management. New Engl J Med @ 1952; 246:19; 744-745.

6 GOLIGHER J C. Surgery of the anus, rectum and colon. 3rd $\overrightarrow{0}$ edition. Bailliere Tindall. London.

7 SHEPHERD J J. Treatment of volvulus of the sigmoid colon: $\vec{\omega}$ A review of 425 cases. Br Med J 1968; 1: 280-283.

\section{Academic Achievements}

$\begin{array}{ll}\text { FRCS } & \text { Maj C A Pailthorpe, RAMC } \\ \text { FRCS Pt. II } & \text { Maj J C Allen, FRCS(Glas) RAMC }\end{array}$

Final Fellowship in Radiology Maj I M Fairley, RAMC MSc in Community Medicine Lt Col I S Creamer, RAMC

\section{Additional Qualifications}

Major $\mathrm{R}$ Thornton, RAMC has been elected an Associateship to Membership of the Faculty of Occupational Medicine.

\section{Honorary Appointments to HM The Queen}

Brig P H Swinhoe OBE appointed Queen's Honora尺 Physician with effect from 25 February 1985 in successig to Lieut General Sir Alan Reay.

Brig D L Macphie appointed Queen's Honorary Surge with effect from 18 March 1985 in succession to Brig A L Peake.

\section{Honorary Consultants to the Army}

Professor M J Tynan, MD, FRCP was appointed Honorary Consultant in Paediatric Cardiology to the Army with effect from 30 January 1985.

Dr N McIntosh BSc, MRCP has been appointed Honorary Consultant in Neonatology to the Army with effect from 20 March 1985.

\section{CORRECTION}

In the February 1985 issue, $\mathrm{Lt} \mathrm{Col} \mathrm{C} \mathrm{G} \mathrm{Callow} \mathrm{was}$ credited with having gained his FRCS, this should have read MSc. Major P Rasor was credited with having gained his MSc, this should have read FRCS. 